\title{
Reading Design Process: A Diagrammatic Approach to Teaching Architectural History
}

\author{
GABRIELA IZAR
}

UniCeub

Contemporaneous debates on architectural form has been linked to sustainability, parameterization and bioarchitecture. In this scenario, what would be the role of history? How the study of history would contribute to understanding the design process in its broad implications? Could the study of precedent open up new educational perspectives? This paper discusses the role of diagrammatic analysis in teaching architecture history, and presents a didactic experience for architectural history students in the fifth semester of an architecture course at a private university in Brasília (Brazil). The particular experience of teaching undergraduates architecture history and design leads to a need to systematize the pedagogical research in order to establish where reflection in these two fields can converge. It is believed that teaching in two such independent fields - history and design - a practice not widespread in Brazilian architecture schools, involve specific methodologies and references. An alternative is to reconsider the premises on which the teaching of history and design are based, focusing on sharing emphases in both courses more effectively, making the students achieve theoretical speculation through the manipulation of formal relationships via diagrammatic procedures. Thus, the examples presented in the paper are intended to show that the teaching of the history of architecture can in some instances take on a kind of dynamic that is analogous to design work. Through this perspective, the role of the history teacher may have similarities with that of the architectural design teacher, in a context in which the teaching of the history of architecture becomes an exploratory construction laboratory.

\section{HISTORY \& PRECEDENT IN THE DESIGN PROCESS}

The teaching of architecture history in Brazil still tends to be confined within specific disciplines, usually taught by experts in aesthetics as well as architecture historians. By the end of the 1990s, dozens of architecture courses sprang up, mostly mirroring public architecture courses, in which the history of architecture is taught in at least four sequential semesters, involving the study of antiquity to the present. In addition, the teaching of history is widespread in public and private higher education institutions as a result of the official regulations that generically require history and theory content in architecture and urbanism courses and faculties. ${ }^{1}$ Although design teachers teach history and vice versa, the Brazilian academic context remains strongly aligned with the traditional teaching of history delimited by specific historiographic approaches, largely separated from the design teaching strategies.
History course content not infrequently presents iconography, constructive techniques and socio-political and geographical contexts in which students are exposed to paradigmatic works employing PowerPoint presentations containing texts, plans, facades, sections, maps and some analytic diagrams. In contrast, within design courses, the overlap between the precedent and the project lies in the way formal readings are at the center of approaches that adopt case studies as a methodology. The study of iconic references tends towards the abstraction of graphic representation of paradigmatic work chosen for the suitability of the theme with regards to the program and the objectives of the design discipline, resulting in the recurrence of analytical studies of modernist and contemporary architecture precedents that emphasize the mapping and abstract reconstitution of spaces, dimensions, infrastructures, implantation, structure and landscape - aspects which are reasonably evident in the documentation available for student research.

The finding by Weddle $(2010)^{2}$ that the teaching of architecture history and design have very different emphases, means and meanings raises the possibility of diffusing the application of design procedures in the teaching of the history of architecture with the perspective of contributing to the updating of didactics, for the effective interconnection of teaching history / theory / design and constructing approaches to the study of operative history based on design paths and reasoning.

Two issues are important when considering the need to update strategies and approaches to teaching history through design: (1) defining the object of historical research; (2) defining the paths upon which results are supposed to be revealed. These two issues involve equipping the students with sufficient means for their own theoretical and practical research. Considering the possible imbrications of history and design, emerges the problem of is how to redefine the means by which research into the historical object can be done, and the role of history of architecture teachers in such a context. An alternative is to reconsider the premises on which the teaching of history and design are based, focusing on sharing emphases in both courses more effectively, looking for procedural intersections that may conduct more naturally to theoretical inferences through design, based on heuristic and constructive speculations upon the precedent. In broad terms, it means making the students achieve theoretical speculation through the manipulation of formal relationships via diagrammatic procedures. 
Rudolf Wittkower, Colin Rowe and Peter Eisenman used the diagram, with its visual and conceptual potential for analysis and interpretations of architecture. Proponents of a formal approach to architecture, they were devoted to analyzing the precedent, scrutinizing paradigmatic Renaissance, Mannerism and Modernism works, revealing patterns and timeless formal attributes in groundbreaking interpretations that contributed to de-stratifying the histography of their respective epochs. Centered on the investigation of what lies behind the discourse of history, their search for the constructive essence that qualifies certain objects as cultural icons established new ways of reading architecture in terms of its formal genealogy. ${ }^{3}$ To a certain extent such a pursuit of the genealogy of form, which requires the materializing of its process of emergence, would anticipate design tendencies proffered from the 1990s, when a new alignment between CAAD and diagrammatic approaches to architecture created the environment for readings of precedent focused on generative procedures for iconic works, rather than their patterns and archetypes. ${ }^{4}$

In order to highlight the formal genealogy of the projects studied, as well as fundamental spatial relationships that qualify these works as representative of a certain aesthetic, in this research the students explore the genealogy of architectural form through analogical models that function as diagrams. ${ }^{5}$ A subject of academic research by the author, the didactic experience consists of a short exercise (lasting about two months) based on diagrammatic strategies of analysis and interpretation of paradigmatic works of architecture and art conceived between the fifteen and eighteenth centuries (from the Renaissance to Rococo).

Analogical diagrams are employed as heuristic conceptual schemas to demonstrate formal-conceptual relationships, focusing on design procedures, providing direct constructive experience of the supports in coordination with digital design, to the production of more precise and optimized artifacts, made with CNC cutting and milling machines, laser cutting, 3D printing of prototypes, paper-cutting plotters and thermoforming machines.

To get the students to incorporate operative reading strategies, prior diagrammatic analysis emphasize the abstraction of layers that articulate aesthetic form in terms of their dynamics of conception. These layers become accessible through analytical and interpretative graphic and analogical 2D and 3D diagrams built to materialize formal-conceptual relations not evident in the usual reading of photographs, drawings and sketches. Assuming that diagrammatic analysis may bring historical reference closer to theoretical production and the architectural project developed in the undergraduate course, through abstraction architectonic structures and formal procedures become subject to successive transformations and reinterpretations that can be deployed as formal-conceptual basis applicable to students' ongoing practice at the design studios.
Based on the research precedents mentioned by the author, the didactic plan presented to the students is based on six premises:

1. Observing the object of study with critical distance and at the same time describing (oral and in writing) the first formal architectural evidences (geometric basis, volume, limits, proportional relations, articulation of horizontal and vertical planes, and so on).

2. Abstracting the object of study in non-evident symbolic / spatial relations.

3. Codifying and manipulating symbolic / spatial relationships in graphical and / or physical elements and exploring static and sequential diagrams, with an emphasis on procedures involving reversible transformations (subtractions, additions, intersections, repetitions, mirroring, and so on) of the architectural form.

4. Incorporating the architectural analysis of works that are not architectural (painting, for example) into case studies to enhance the ability to codify and interpret formal structures/patterns common to different artistic expressions that contribute to elucidating formal analogous conceptual problems.

5. Conceptualizing the essential procedure of the work studied in one or more models that function as analogical diagrams.

6. Writing up the evidence and relationships constructed diagrammatically in descriptive and interpretative text on the process.

The following description presents a sample of four students' diagrammatic analysis and models, followed by concluding remarks that briefly mention three recent cases.

Villa Rotonda, Andrea Palladio: the notion that the work by Andrea Palladio is marked by formalism and mathematical rationality is widely explored in the classic texts on the history of architecture. ${ }^{6}$ Referenced by Palladio's I quattro libri dell'architettura (1570) and online digital models, the students constructed their own digital models in Sketchup and 3D printer. Here the students were asked to formalize Peter Eisenman's interpretation that in Palladio's villas space is generated through layering vertical planes. A digital model of Villa Rotonda's main vertical slices was 3D printed and rearranged as an open structure that emphasized Palladio's principle of composition with planes, instead of volumes. The reduced scale of the model required precise drawings, given the thicknesses of the facades, stairs, ornaments, sculptures, columns and capitals, in contrast to the abstract configuration of the final analogical diagram. Villa Rotonda reappears in the students' formal reading as an open box, broken up into white pieces molded into planes and solids, assembled as a diagram unfamiliar to the historical illustrations that commonly support Palladio's works (figure 1). 


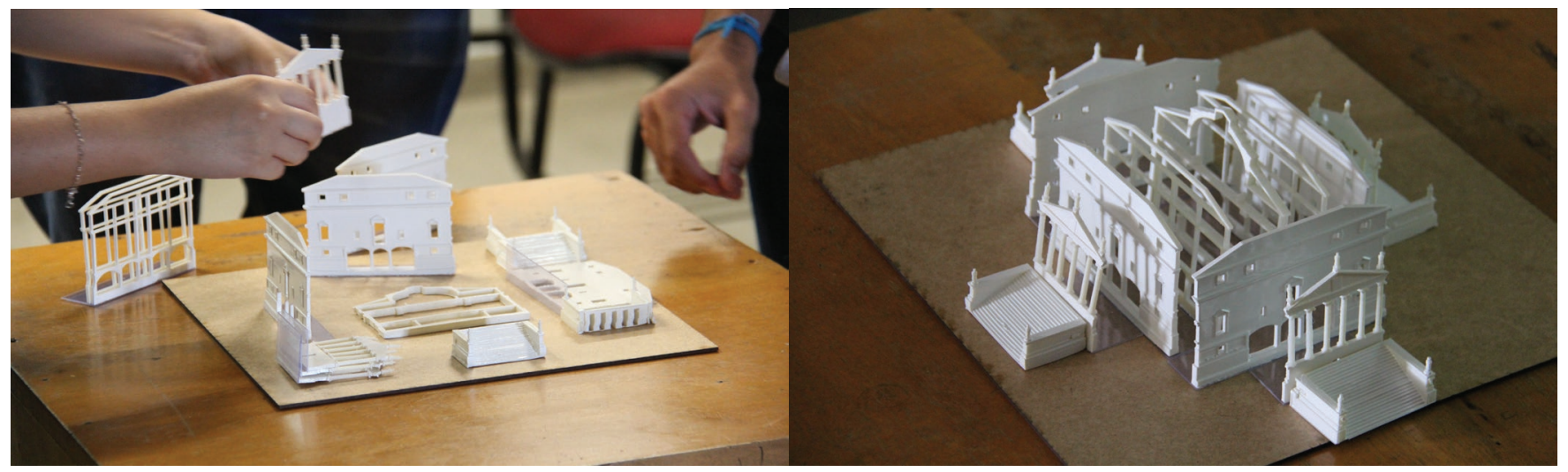

Figure 1. Analogical diagram of Villa Rotonda showing assembly of the interactive model and final stage. Student's public presentation; analogic diagrams built in 3D printer. Students: Carlos Tibery, Diego Kern, Isabela Andreotti, Igor Faria.

Olympic Theater, Andrea Palladio and Vicenzo Scamozzi: the theater is one of the main contributions of Baroque aesthetics to modern culture. The students explored this content within the reconstructing the Olympic Theater as a series of vertical slices that model the empty interior space and the singular projection of the stage over the audience. By doing that, students revealed the interior mass of space as a folded plane designed as a line that connects floor, ceiling and wall, through an extension covered by the extreme portion of the stage up to the far side of the audience area. This line path that draws the wood slice planes somehow prefigures the baroque thought of space in terms of its topological attributes. Following the discovery of a seemingly simple detail, evidenced in the construction of cuts of the building's main room interior, the students inferred about a fundamental spatial property of Baroque theater: the expansion of the stage in relation to the audience zone.

Within diagrammatic analysis, this inversion of proportion was revealed in a uncommon analogical diagram composed of vertical sections of the inner space produced with laser-cut MDF. The relationship was concealed in the deformations of the floor angle and false walls configured in the distorted perspectives created by Scamozzi. The pieces were then assembled as a structural 1:100 model and adjusted for visualization of the empty mass in the internal environment. This model also brought about an understanding of the possibility of virtually representing the empty mass between the ceiling, walls and floor, the stage and audience. The students' inference from the model was that in this paradigmatic case the spectator felt projected into the stage by the proximity of different zones, and departing from this conclusion, the model could be used also as a general zoning schema for a new theater's design. Beyond this assumption, they could understand the analogical model as a design device to imagine on a formal-theoretical plane that the Olympic Theater is on the threshold between Mannerism and Baroque (figure 2).
Palazzo Strozzi, Benedetto da Maiano: italian Renaissance palaces contain the foundations of modern organization of urban space and landscape - rectilinear, modulated, regular, and uniform. This was a new treatment of volume, transformed by two essential formal operations: the subdivision of the facade into hierarchically arranged sectors; and the subtraction of the nucleus from the building in order to restore to the interior a place of social interaction - the cortile - which begins to integrate the domestic world in a regulated and permeable way, against the fortified types of the Middle Ages. How can this relationship be achieved but by the schematic approximation between exterior and interior? Taking the facade as a diagram, the students abstracted the Renaissance wall into its compositional planes, thus recovering the constructive thinking that gave rise to it. An interest in the regularity of civil fifteenth-century architecture led the students to choose the Strozzi Palace as a paradigm of Renaissance relationship between ratios and space. The process, which began with the survey of plant, cuttings and facades in internet and books, was followed by the problem of making the exterior and interior explicit at the same time, so as to articulate, in one field of view, the situation of the exterior facade in its close compositional relation to the internal facade, an original element of the architecture of the palazzi, and fundamental complement of the cortile. Cut in half, the model is a diagram of the Renaissance schema, at the same time that it references the regulatory outline of the outer vertical planes, as well as the horizontal division that defines the scale of the building according to humanistic precepts of proportion/symmetry/ hierarchy.

The study, formulated in two versions, began with a balsa wood model, preceded by two-dimensional drawings of the vertical planes, printed on paper to guide the positioning of classic windows and columns. The second, more schematic and precise model, constructed with laser-cut MDF components, explored, to a lesser extent, the same relationships, and the geometric rusticated stone as an integral component of the facade plane's composition. The 


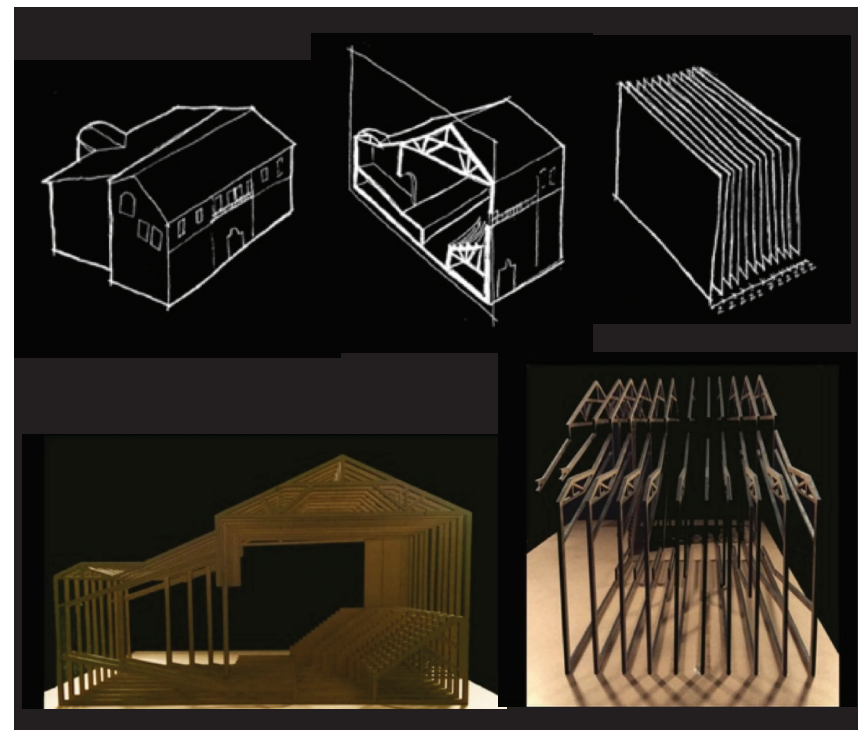

Figure 2. Olympic Theater's graphic and analogical diagrams built from laser cut MDF. Students: Filipe Bresciani, Ludmila Bottechia, Marcos Tibery, Maria Clara Nobre.

students' experience in making the second model allowed reinforcing some formal and constructive aspects discovered in the previous model.

The experience of studying historical precedent, operating with its formal structures through models expressing fundamental relations, is nothing new. Le Corbusier possibly detected the Renaissance logical schema and applied it to his own compositional schema. ${ }^{7}$ But now, the idea of the continuous transposition of historical structures into new possibilities for the present certainly infiltrated the constructive process in the students' analytical and interpretative work (figure 3).

Palazzo del Te, Giulio Romano: students' diagrammatic work focused on the same Mannerist problem of juxtaposing layers departing from a Renaissance generative pattern, but now by the procedure of confronting two formal-conceptual schemas: (1) the composition of the Renaissance vertical plane and (2) the composition of the Mannerist vertical plane. The students demonstrated that (1) is structurally contained in (2), reinforcing, through formal analysis, a widely-accepted hypothesis in theory that the typical Italian Mannerist composition of facades evolved from the typical Renaissance composition and that this evolution can be identified at a deep level of the work - that is, from the base and formal architectural procedure employed by Romano.

Students isolated the planes corresponding to the facades and redrew them according to the different patterns and ratios, decoded through drawing upon photos and technical drawings. The decomposition of thick walls into many thin gridded planes originated an analogical layering diagram that translates Romano's procedure of designing facades as juxtaposed planes, leading students to understand a facade as an index of formal-conceptual relationships.

This involved a deductive and a creative component, as the analogical diagram produced by the group stemmed from redesigning the original facades, and the creation of several other planes, taking the former as a parameter. This corresponds conceptually and formally to Romano's conception of what would become one of the most heterodox of fifteenth-century palaces, in which no surface is repeated while reinforcing the identity of the other by containing the grid as a formal basis in the compositions of the facades.

Comprised of PVC planes made by a 3D printer, the modeldiagram reinforces the formal problem investigated in the layout of the opaque and transparent layers, in close correspondence with the design of the building plan, represented in two dimensions to show that despite its volumetric and heavy appearance, the Palazzo del Te is essentially an investigation of vertical plane composition, a quality that reinforces the distinction between Romano's mannerism from his predecessor Rafael, here highlighted by the operative quality of the students' analysis (figure 4).

The students' first analysis identified more evident aspects that gradually increased in complexity through digital and analogical modeling, bringing about formal assemblages that made explicit original structural qualities previously sought and the unusual unfolding of schemes that were initially very primitive. In a diagrammatic study of Renaissance perspective, a team of students explored the "architecture" of the Holy Trinity fresco (Masaccio, 1428), based on previous readings and diagrams (figure 5a). Analogical diagrams were drawn up to break down the planes, from which three-dimensional models were built. The students could then visualize more clearly the ambiguity between the compositional rigor of proportional relations and the informality of the folds that make up the capes worn by the figures below the image of Jesus Christ.

Throughout the supervision, another team of students were encouraged to explore the diagrammatic quality of the investigation process. For example, the work done by a team of students who explained the use of ratios in the comparative study of three villas by Andrea Palladio started with mapping relations of harmonic proportion, which were translated into musical scales to be played on a small piano (figure 5b). The students created visually and sonically tangible relations between space and sound patterns in the villa environments in investigation that sheds light on the very essence of the diagram - that is, to operate, as claimed by Kenneth Knoespel, symbolic transpositions. ${ }^{8}$ 

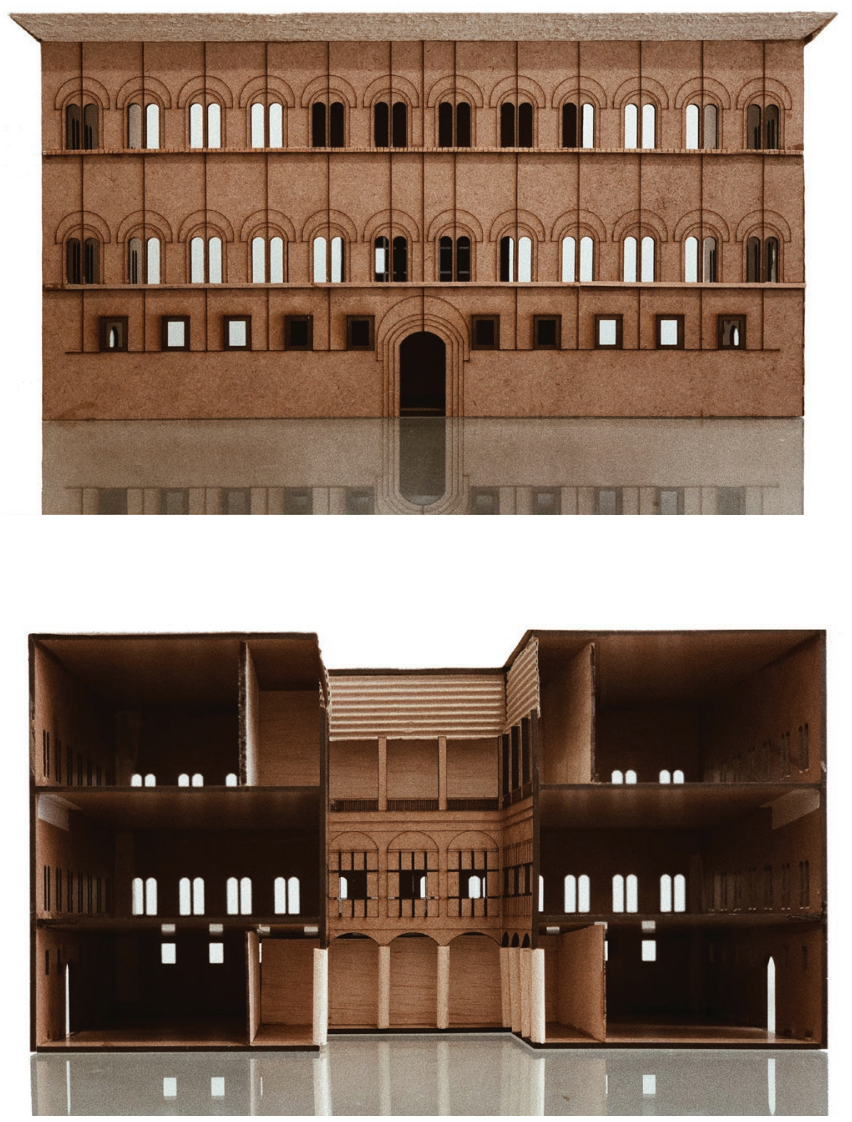

Figure 3. Palazzo Strozzi analogical diagram confronting the proportional relationship between façade $x$ cortile, built from laser cut MDF. Students: Ana Ramalho, Emanuelle Prates, Fernanda Cruz, Maria Gabriela Cunha.

The diagrammatic quality of the exercise was maximized by the use of materials to construct three-dimensional masks of planimetry and elevation grades and two-dimensional graphics of hidden dimension lines arranged as opaque and transparent planes, according to the hierarchy of the sound patterns of musical scales and geometric basis adopted by Palladio in the villas' schematics. The choice of materials, colors and design reinforced, therefore, the singularity of the procedure of repetition and variation in the work by this architect.

As part of the same problem of materializing the revolution of Italian mannerism, one of the teams focused on providing evidence for the procedure of opening the Renaissance box and the configuration of the sixteenth-century villas scenographic character, taking the Villa Giulia (Vignola, 1551 ) as a paradigm (figure $5 c$ ). The formal procedure was translated into sequential analog and digital diagrams, based on study models, subsequently photographed and edited in stop motion animation.

The emphasis given to sequential transformation diagrams was to register the process heuristics and lead students to
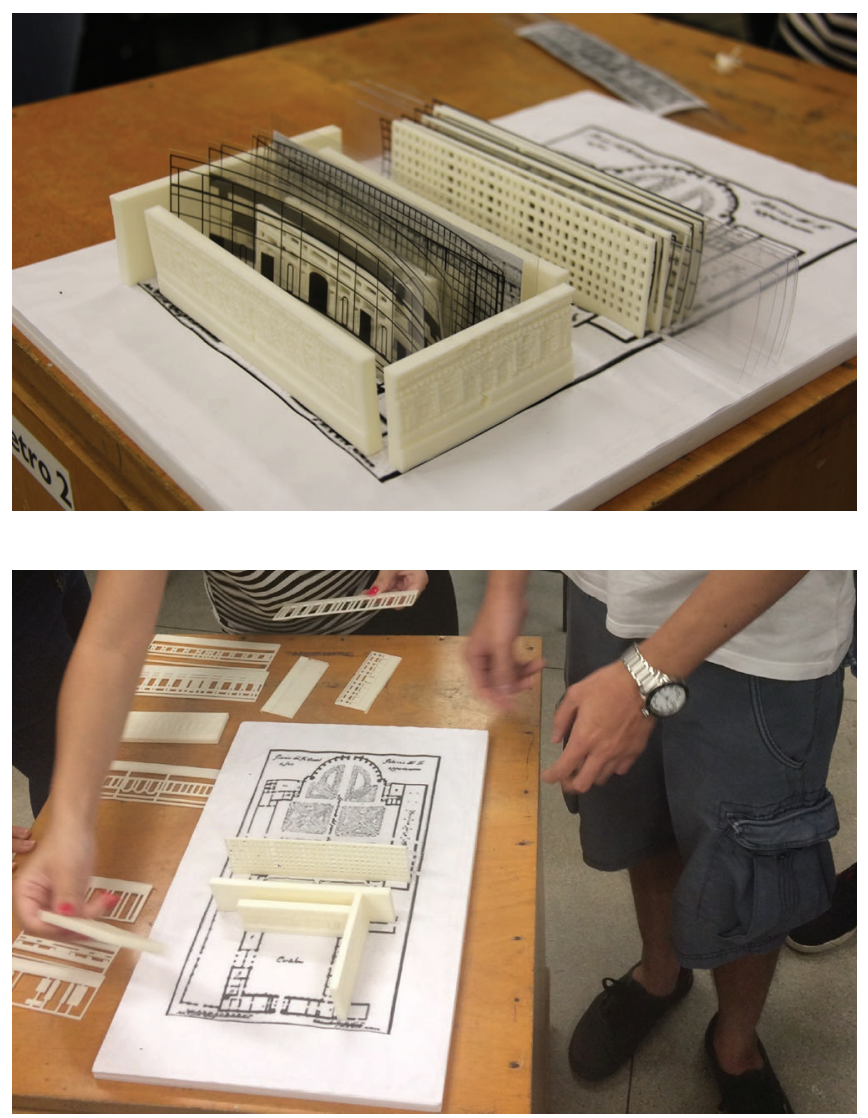

Figure 4. Students presenting Palazzo del Te interactive diagrams, made of PVC, prototyped by a 3D printer. Students: Fernanda Venâncio, Jessica Alves, Leonardo Yen, Mariana Machado. Photographs: Zaskia Fritsche.

an understanding of the constructive dynamics inherent in the architectural design process. The students began to observe the building as a transformative diagram, as each new procedure operated in the volumes / planes (division, subtraction, juxtaposition, intersection) configured distinct environmental effect, which would lead to the interpretation of directions and the drama of Mannerist architecture as an aesthetic quality linked to the historical context of the work, also to be potentially formalized in a new architectural project that explores the opposite attribute in terms of its formal-conceptual program.

The didactic plan concluded with students being asked to write an assignment based on some pre-defined topics formulated by the teacher, describing their work phases, means employed, formal procedures performed within the diagrammatic analysis and theoretical conclusions. Writing aims to develop the students' ability to explain the constructive process in its aesthetic aspects in text that involves specific concepts and language to designate spatial relationships belonging to architecture and the type of constructive process the students have become involved in. 

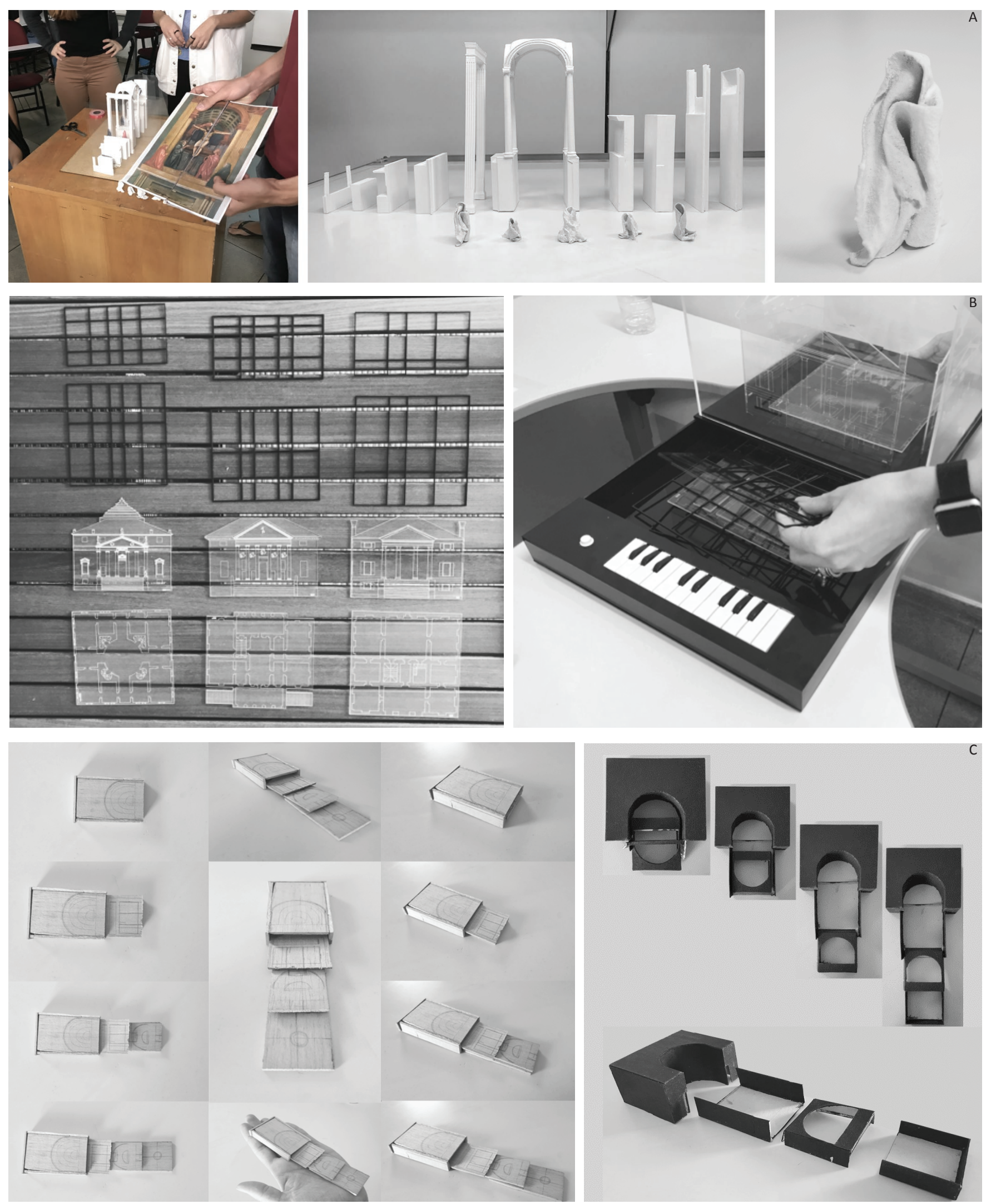

Figure 5. Top row, students presentation of Masaccio's holy trinity composition layering - students: Gabriel Rodrigues, Karynne Soares Santos, Leticia Vieira de Oliveira, Vítor Silva; center row, Palladio's villas vertical layers separated then assembled as an interactive sound box - Students: Beatriz Leivas, Daniela Bessa, Isabella Salomão, Juliana Oliveira; bottom row, Villa Giulia sequential analogical diagrams made with balsa wood (left) and cardboard (right) - students: Letícia Machado, Maria Carolina Schulz, Marina Sattamini, Tamara Araujo, Yara Vidal. 
The team's works were completed with a public presentation of all the content - texts, diagrams, models and videos - organized together with a panel. Phases and means of construction were thus graphically, physically and textually cumulatively linked, leading the students to explore and aggregate, in each mode of analytical reading (sketches to notes, to collages, to analog / digital study models, back to notes, to sequential diagrams, videos, to text, to the panel, and so on) the potential theoretical-formal content provided by these different modalities of expression and which therefore approach the nature of architectural design.

The students faced some difficulties during the work. One was the limited supply of material offered by local companies, as well as equipment and technology for digital fabrication and model making, which made the need to plan and implement the institution's own laboratory infrastructure more evident. In addition, most students are competent users of Photoshop, SketchUp, and AutoCad but the work would reach another level when considering the use of advanced modeling programs - Rhinoceros, Grasshopper and 3DSMax.

Nevertheless, the quality of the analogical models, the possibility of using them as teaching tools, the level of student involvement in the process, and the students improved understanding of essential architectural issues are aspects that demonstrate the importance of this approach to historical precedent, within which students had to be responsible for structuring their own work process and get involved with their architectural design skills.

The redesign of precedent involved uncover the genealogy of formal conception, therein considering the original constructive idea, the materials expression, dimensional patterns adopted, and so on. These aspects are associated with the constructive research of the model itself and depended on the predefinition of appropriate scales for the diagrams and materials compatible with the formal problem surveyed in the work, and the organizational scheme of the components in the model. It is believed that the research led the students to a theoretical level for reading the historical precedent, when aesthetic considerations were then discussed through the formal manipulation of conceptual relationships within the diagrams.

Teaching design students who are also students of the history of architecture suggests the possibility of establishing a significant increase in the way a formal reading of precedent may operate. The distancing promoted by the abstraction of the historical object extends the visualization of procedures that are not restricted to historical precedent, but which can be operated on in proposing and solving problems in their own projects in a design studio. As the students are challenged to analyze the historical object from successive diagrammatic restructurings, they begin to experience the course's conceptual-formal constitutive transformation process inherent to the practice in architectural design.
The examples presented are intended to show that the teaching of the history of architecture can in some instances take on a kind of dynamic that is analogous to design work through the organization of a process in which students are involved in a constructive process coordinated with conceptual inferences that help to articulate theoretical assumptions. Through this perspective, the role of the history teacher may have similarities with that of the architectural design teacher, in a context in which the teaching of the history of architecture becomes an exploratory construction laboratory.

In being an integral part of a compulsory architecture course, each semester it has been possible to aggregate results not previously traced, which is directly influenced by students' different levels of motivation and theoretical development regarding their inferences when confronting syllabi theoretical topics. This pedagogical research is therefore a work in progress, since the students involved in it have been contributing to the transformation of means and approaches from their particular learning experiences.

In addition to its applicability in the field of architectural historiography, diagrammatic analysis mediated by analogical models provides students with an active operative attitude to the historical object, enabling them to examine and articulate formal-functional problems within the discipline of architectural design, through systematic transformation procedures previously explored within the framework of studying history. The work resulted in interpretations that provide schemas for future students understand more complex contents presented during the history course, with the participation of former students in short lectures during the semester where they can explain their theoretical inferences brought along the process of research.

Diagrammatic analysis is not enough to overcome the knowledge of precedent and in this regard this research has reached its limit. Although having gathered together alternative readings of architectural masterpieces within the formal realm - because that is where we set out to understand the things - this work seeks its proper locus between two much broader and fundamental disciplines to which culture will always be indebted: that opened up by designers, and that opened up by the historians.

\section{ENDNOTES}

1 "Institutes National Curricular Guidelines for Undergraduate Courses in Architecture and Urbanism," MEC (Brazil's Ministry of Education), Resolution No. 2, Subsection V, 2010.

2 Robert Weddle, "Precedent, Diagram, and the Activation of History," 98th ACSA Annual Meeting Proceedings, Rebuilding, eds., Bruce Goodwin and Judith Kinnard (Washington, D.C.: ACSA Press, 2010), 1.

3 Anthony Vidler, interview with Gabriela Izar. Brasilia, DF. 2012."Diagrammatic: Description and Creation of Forms in the Serial Architecture of Peter Eisenman," Doctoral thesis, University of São Paulo, São Paulo, (2015), 85. 
4 On Peter Eisenman's course at Yale, see: https://www.architecture.yale.edu/ faculty/316-peter-eisenman; On the history turn within architectural design see "Intersections: Dialogues of Architecture \& History," presented at the Society of Architectural Historians Conference, Pasadena, 2016; and "In Practice: History as Research and Design Strategy," presented at the ACSA Annual Meeting, Detroit, 2017. On professor Andrew Saunders research, see: https://pricelab.sas.upenn. edu/projects/baroque-topologies.

5 Students involved in the works presented in this paper: Fernanda Venâncio, Jessica Alves, Leonardo Yen, Mariana Machado; Ana Ramalho, Emanuelle Prates, Fernanda Cruz, Maria Gabriela Cunha; Carlos Tibery, Diego Kern, Isabela Andreotti, Igor Faria; Filipe Bresciani, Ludmila Bottechia, Marcos Tibery, Maria Clara Nobre; Beatriz Leivas, Daniela Bessa, Isabella Salomão, Juliana Oliveira; Letícia Machado, Maria Carolina Schulz, Marina Sattamini, Tamara Araujo, Yara Vidal; Gabriel Rodrigues, Karynne Soares Santos, Leticia Vieira de Oliveira, Vítor Silva.

6 Rudolf Wittkower, Architectural Principles in the Age of Humanism (New York: W.W. Norton \& Company, Inc., 1949; 1971).

7 Colin Rowe, "The Mathematics of the Ideal Villa: Palladio and Le Corbusier Compared, Architectural Review (1947).

8 Kenneth J. Knoespel, "Diagrammatic Transformation of Architectural Space," Philosophica 70 (2002): 13. 